Research Article

\title{
Clinical Profile of Patients of Leptospirosis and Its Outcome
}

\author{
Vikas Ratnaparkhe', Rajashree Ratnaparkhe ${ }^{2}$, Shilpa Vaishnav ${ }^{3}$ \\ ${ }^{1,2,3}$ Dr. Hedgewar Rugnalaya Hospital, Aurangabad, Maharashtra, India. \\ DOI: https://doi.org/10.24321/2349.7181.201916
}

I $\mathbf{N} \quad \mathbf{F} \mathbf{O}$

\section{Corresponding Author:}

Ratnaparkhe Vikas, Dr. Hedgewar Rugnalaya Hospital, Aurangabad, Maharashtra, India.

E-mail Id:

vikasrr25@gmail.com

Orcid Id:

https://orcid.org/0000-0002-7731-2921

How to cite this article:

Ratnaparkhe V, Ratnaparkhe R, Vaishnav S. Clinical Profile of Patients of Leptospirosis and Its Outcome. J Adv Res Med 2019; 6(3): 19-22.

Date of Submission: 2020-01-24

Date of Acceptance: 2020-02-29

\section{$\begin{array}{llllllll}\mathbf{A} & \mathbf{B} & \mathbf{S} & \mathbf{T} & \mathbf{R} & \mathbf{A} & \mathbf{C} & \mathbf{T}\end{array}$}

Background: Leptospirosis is an emerging spirochetal zoonosis worldwide. It is underreported and under diagnosed in India. The clinical manifestations of Leptospirosis range from an asymptomatic illness, self-limiting systemic infection to severe and potentially fatal disease. Approximately 1 million severe cases occur per year.

Aims and Objectives: To study the clinical profile of acute onset fever (less than 7 days) that are IgM positive for leptospira and to study their in hospital outcome.

Methods: This observational study was conducted in Dr. Hedgewar Hospital, Aurangabad, Maharashtra. The IgM positive leptospirosis patients admitted during January 2014 to December 2018 were included in the study. The information on demographic and clinical profile of these patients was recorded and analyzed based on modified Faine's criteria. Their in hospital outcome was assessed.

Result: The study included 62 leptospirosis IgM positive patients. The mean age was $38.14 \pm 15.84$ years. All patients presented with fever. Acute Respiratory Distress Syndrome (ARDS) was the most common complication seen in $48.38 \%$. Case Fatality Rate (CFR) was found to be $16.12 \%$ (10 out of 62 ) patients.

\section{Conclusion}

- High proportion of cases indirectly reflects the endemic nature of the disease.

- The clinical presentation of leptospirosis is highly protean and may vary from sub-clinical to mild illness to life-threatening complications and death.

Keywords: Leptospira, Rainy season, Leptospira IgM, Liver Function Test, Acute Respiratory Distress

\section{Introduction}

Leptospirosis is a zoonosis caused by spirochetes of the genus Leptospira and is prevalent worldwide. ${ }^{1}$ The species has almost 20 serogroups and 200 serovars. Current information on global human leptospirosis demonstrates Case Fatality Rate (CFR) of nearly $10 \% .{ }^{1}$ Weil's disease is a severe leptospira infection. Most cases occur in men and peak incidence is during the rainy season. ${ }^{1}$ The major burden of the disease is in developing countries. ${ }^{2}$ The incidence of leptospirosis is estimated to be 10 or more per 100,000 people in the tropics. ${ }^{1}$ Humans are accidental hosts; the primary reservoir hosts include infected animals such as 
rodents, dogs, cattle and pigs. The infection is acquired by humans through direct or indirect contact with water or soil contaminated by the urine of infected animals. ${ }^{2}$ The high risk groups constitute agricultural laborers, sewage workers, animal handlers and veterinarian. ${ }^{3}$

The isolation rate of the causative organism from clinical specimens is low due to indiscriminate use of antibiotics and also difficult and expensive isolation techniques, currently, serological techniques remain the cornerstone of diagnosis. ${ }^{4}$

\section{Aims and Objectives}

To study the clinical profile of patients of seropositive leptospira and its outcome.

\section{Materials and Methods}

This was a single institutional observational study conducted at Dr. Hedgewar Hospital, Aurangabad. The study was approved by ethical committee Dr. Babasaheb Ambedkar Medical Research Society. Purpose of the study was carefully explained to the patients and consent was taken.

\section{Inclusion Criteria}

- $\quad$ Age more than 15 years.

- Fever $<7$ days.

- $\quad$ ELISA IgM positive for leptospirosis.

The detailed history and presenting symptoms were noted. Thorough clinical examination was done. The laboratory and radiological tests were carried out. The patients were treated with Injection Doxycycline and other supportive care like fluid resuscitation, blood component transfusions, vasopressors, dialysis and respiratory support was provided as and when needed. The data was analysed and presented. Patients with leptospirosis were diagnosed by using modified Faine's criteria ${ }^{5}$ (score $>25$ ). The enzyme immunoassay for IgM with value more than $20 \mathrm{U} / \mathrm{ml}$ was considered as positive for leptospirosis.

\section{Result and Observations}

A total of 62 patients were evaluated with a mean age of $38.14+/-15.84$ years (30M/32F). Of these $49(79 \%)$ had come from rural areas and $13(21 \%)$ were staying in urban Areas. $10(16 \%)$ patients died in the hospital, of these 7 patients were from rural area and 3 patients were from urban area.

Table I.Seasonal Distribution

\begin{tabular}{|c|c|c|}
\hline \multicolumn{2}{|c|}{$(\mathrm{n}=62)$} \\
\hline Season & No. of Patients & Percentage \% \\
\hline Rainy & 38 & 61.2 \\
\hline Winter & 13 & 20.9 \\
\hline Summer & 11 & 17.7 \\
\hline
\end{tabular}

The incidence of Leptospirosis was observed more in rainy season.
Table 2.Symptomwise Distribution

$(n=62)$

\begin{tabular}{|c|c|c|}
\hline Symptoms & Frequency & Percentage \% \\
\hline Fever & 62 & 100 \\
\hline Body Ache & 54 & 87.09 \\
\hline Nausea \& Vomiting & 50 & 80.64 \\
\hline Dyspnoea & 29 & 46.77 \\
\hline Swelling over feet & 17 & 27.41 \\
\hline Giddiness & 14 & 22.58 \\
\hline Irritability & 11 & 17.74 \\
\hline Unconsciousness & 7 & 11.29 \\
\hline PR Bleed & 3 & 4.83 \\
\hline Loose Motion & 3 & 4.83 \\
\hline
\end{tabular}

Table 3.Complications in Leptospirosis

\begin{tabular}{|c|c|c|c|c|}
\hline Complication & $\begin{array}{c}\text { No. of } \\
\text { Patients }\end{array}$ & $\begin{array}{c}\text { Per- } \\
\text { centage } \\
\%\end{array}$ & $\begin{array}{c}\text { Sur- } \\
\text { vivors }\end{array}$ & $\begin{array}{c}\text { Non- } \\
\text { survivors }\end{array}$ \\
\hline $\begin{array}{c}\text { Throm- } \\
\text { bocytopenia }\end{array}$ & 45 & 72.58 & 37 & 8 \\
\hline Deranged LFT & 32 & 50.61 & 23 & 9 \\
\hline ARDS & 30 & 48.38 & 20 & 10 \\
\hline Shock & 16 & 25.8 & 6 & 10 \\
\hline $\begin{array}{c}\text { Ence- } \\
\text { phalopathy }\end{array}$ & 9 & 14.51 & 1 & 8 \\
\hline ARF & 9 & 14.51 & 6 & 3 \\
\hline Coagulopathy & 5 & 8 & 5 & - \\
\hline $\begin{array}{c}\text { Pericardial } \\
\text { Effusion }\end{array}$ & 1 & 1.6 & 1 & - \\
\hline Quadriparesis & 1 & 1.6 & 1 & 1 \\
\hline
\end{tabular}

$19.35 \%$ (12 patients) were also found to be Dengue IgM positive, however their positive status could not be reconfirmed by molecular tests.

Table 4.Comorbidities Observed In Patients

\begin{tabular}{|c|c|}
\hline Comorbidities & Frequency \\
\hline DM & 4 \\
\hline Hypertension & 4 \\
\hline IHD & 2 \\
\hline Pregnancy & 3 \\
\hline MCTD & 1 \\
\hline Asthma & 1 \\
\hline Seizure Disorder & 1 \\
\hline
\end{tabular}

10 patients were having comorbid conditions like Diabetes 
Mellitus (D.M), Hypertension, Ischemic Heart Disease (I.H.D). Of these 10 patients 4 patients died. No deaths were reported in pregnant patients.

Table 5.Multi Organ Dysfunction Syndrome (MODS)

\begin{tabular}{|c|c|}
\hline MODS & No. of Patients (35) \\
\hline Survivors & 25 \\
\hline Nonsurvivors & 10 \\
\hline
\end{tabular}

35 (56.45\%) patients suffered MODS. Death was reported in 10 patients suffering from MODS.

\section{Discussion}

Leptospirosis is an infectious disease caused by the spirochete Leptospira interrogans, which has self-limiting systemic infection to severe and potentially fatal disease. Leptospirosis is usually the disease of rainy season. The study done by Patil $V$ et al showed maximum incidence in the month of July and August. $78.26 \%$ patients were farmers and $21.73 \%$ were laborers. ${ }^{6}$ In our study $61.2 \%$ patients presented during rainy season. $79 \%$ of our patients were from rural area. Symptomatic leptospirosis begins acutely with headache, fever, malaise, myalgia, conjunctival congestion and rash. The common presenting symptoms observed in our study were fever in $98.38 \%$, body ache in $87.09 \%$, nausea \& vomiting in $80.64 \%$ and dyspnea in $46.77 \%$ patients. Rash was not a presenting feature in our study. $T$ hrombocytopenia usually occurs in $50-93 \%$ of leptospirosis patients ${ }^{7}$ which is an indicator a worldwide distribution. The clinical manifestations of Leptospirosis range from an asymptomatic illness, of severity of the disease The mechanisms are peripheral platelet consumption; immune mediated platelet destruction and inhibited platelet production by bone marrow. ${ }^{6}$ In our study the incidence of thrombocytopenia was $72.58 \%$. The study done by Sharma et al and Pappachan et al showed thrombocytopenia in $86.6 \%$ and $65.8 \%$ respectively. ${ }^{4,8}$ The severe form of leptospirosis is characterized by jaundice, Acute Kidney Injury (AKI) and hemorrhage known as Weil's disease caused by the Serovars Icterohaemorrhagiae, Copenhageni and Lai. AKI and hepatic dysfunction are frequently associated with thrombocytopenia in leptospirosis. Our study showed Weil' syndrome in $30.43 \%$ patients which was similar to the incidence observed in the study conducted by Patil V et al i.e $30.43 \%{ }^{6}$ The incidence of Weil's syndrome was $69.8 \%$ in the study done by Pappachan et al. ${ }^{4}$

In our study the incidence of hepatitis was $50.6 \%$ and AKI was $14.5 \%$. In the study done by Virendra Patil et al the incidence of hepatitis was $69.56 \%$ and AKI was $52.17 \% .{ }^{6}$ Hyperbilirubinemia is the most frequently noted laboratory abnormality ${ }^{9}$ Andrade et al. ${ }^{10}$ showed non oliguric acute kidney injury and hypokalemia. The tubular function alterations precede a decrease in the glomerular filtration rate, which could explain the high frequency of hypokalemia in leptospirosis. In our study, we had $26.08 \%$ patients with hyperkalemia and $30.43 \%$ patients with hypokalemia. It may be due to delay in presentation, anuria at the time of admission and or different epidemiological serovar. Daher et al. concluded age $>40$ years, hyponatremia, elevated serum creatinine, low arterial $\mathrm{pH}$, high levels of AST, crackles and direct bilirubin levels would be useful markers for patients with oliguric AKI in leptospirosis. This is comparable with our results. ${ }^{10}$

The other severe form of leptospirosis is hemorrhagic pneumopathy. It is predictor of acute respiratory failure which is one of the main causes of mortality . In our study ARDS was observed in $48.4 \%$ patients. Patil $\mathrm{V}$ et al., ${ }^{6}$ demonstrated the incidence of ARDS in $30.43 \%$ patients. In a study done by Sharma et al. ${ }^{8}$ ARDS was observed in $30 \%$ of thrombocytopenic patients. The mortality shown by various researchers: Tantitanawat et al. ${ }^{13} 18.50 \%$, Vijayachari et al. ${ }^{9} 10 \%$ to $15 \%$. our study showed a mortality of $16.12 \%$.

Vasculitis is an important cause of bleeding in leptospirosis. Contributory factors are thrombocytopenia, capillary endothelial damage, coagulation defects from hepatic dysfunction, consumptive coagulopathy and DIC. ${ }^{11}$ Bleeding in vital organs is one of the leading causes of death in leptospirosis. ${ }^{12}$ Our study showed the incidence of coagulopathy in $8 \%$ patients. DIC was observed in $8.69 \%$ patients by Patil V et al.

In the study done by Dupont et al. ${ }^{11}$ Multivariate logistic regression demonstrated that five factors were independently associated with mortality: dyspnoea, oliguria, leukocytosis more than $12,900 / \mathrm{mm} 3$, repolarization abnormalities on electrocardiograms and alveolar infiltrates on chest radiographs (Figure 1).

We had $12.9 \%$ patients with neuroleptospirosis. Mathew et al. ${ }^{4}$ in his pathological study of brain in five cases revealed encephalitis. He showed that deep altered sensorium and raised CSF protein were two poor prognostic indicators. We had one patient with Acute Demyelinating Encephalomyelitis (ADEM) who succumbed within $48 \mathrm{~h}$ of admission. In study done by Patil V et al. ${ }^{6} 30.43 \%$ patients had neuroleptospirosis. Panicker et al. ${ }^{13}$ showed paraparesis as initial presentation in $42.5 \%$ patients. $7.5 \%$ patients had a lower motor neuron paraparesis. Myelopathy was seen in $17.5 \%$ patients, myeloradiculopathy in $17.5 \%$, and Guillain-Barré syndrome-like presentation in $7.5 \%$.

\section{In Summary}

Total 62 IGM positive leptospirosis patients with mean age of $38.14( \pm 15.84)$ years. $79 \%$ patients were from rural background. $52 \%$ patients were females. $61.2 \%$ patients presented in rainy season. Common presentations in our study were fever (100\%), body ache ( $87.09 \%)$, nausea \& 
vomiting (80.64\%) and dyspnea (46.77\%). Rash was not a present.

The common complications observed were thrombocytopenia $72.58 \%$, Deranged liver parameters 50.6\%, ARDS $48.38 \%$, pneumonitis $40.32 \%$, Shock $25.8 \%$, and encephalopathy $14.51 \%$. Dengue IgM was positive in $19.4 \%$ patients. Case Fatality Rate (CFR) was found to be $16.12 \%$.

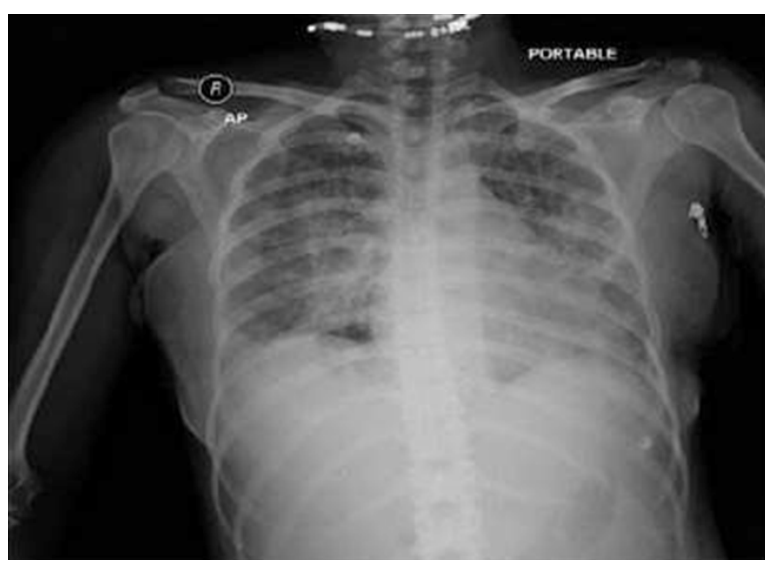

Figure I.Radiograph of a patient who died of leptospirosis showing bilateral fine granular opacities, pronounced hypoaeration in the pulmonary parenchyma

\section{Conclusion}

- High proportion of cases indirectly reflects the endemic nature of the disease.

- The clinical presentation of leptospirosis is highly protean and may vary from subclinical to mild illness to life-threatening complications and death.

- Unavailability of microscopic evidence of leptospirosis remained the lacunae of our study.

- $\quad$ There is a need for such studies in areas of heavy rainfall and water stagnation where the incidence may be much more

\section{Conflict of Interest: None}

\section{References}

1. Jameson JL, Fauci AS, Kasper DL, Hauser SL, Dan L Longo JL. Harrisons Prnciples Of Internal Medicine. $20^{\text {th }}$ ed. by J. Larry Jameson, Anthony S. Fauci, Dennis L. Kasper, Stephen L. Hauser, Dan L. Longo JL, editor. New York: McGrawHill Education; 2018; 1290-1291. Available from: https://accessmedicine.mhmedical. com/book.aspx?bookID=2129.

2. Karande S, Bhatt M, Kelkar A, Kulkarni M, De A, Varaiya A. An observational study to detect leptospirosis in Mumbai, India, 2000. Arch Dis Child 2003; 88(12): 1070-1075. Available from: https://adc.bmj.com/ content/88/12/1070.long [PubMed/ Google Scholar].

3. Pappas G, Papadimitriou P, Siozopoulou V, Christou L, Akritidis N. The globalization of leptospirosis: worldwide incidence trends. Int J Infect Dis 2008; 12(4): 351-357. Available from: https://www.ijidonline.com/article/ S1201-9712(07)00195-6/fulltext [PubMed/ Google Scholar].

4. Pappachan MJ, Mathew S, Aravindan KP, Khader A, Bharghavan PV, Abdul Kareem MM et al. Risk factors for mortality in patients with leptospirosis during an epidemic in northern Kerala. Natl Med J India 2004; 17(5): 240-242. [PubMed/ Google Scholar].

5. Shivakumar S, Shareek PS. Diagnosis of leptospirosis utilizing modified Faine's criteria2. Journal of Association of Physicians of India 2004; 52: 678-679. [ResearchGate/Google Scholar].

6. Patil H, Agrawal V, Patil V. Clinical profile and outcome of leptospirosis at tertiary care centre in western Maharashtra. J Acad Med Sci 2012; 2(1): 30-37. Available from: http://www.e-jams.org/article.asp?issn=22494855; year=2012; volume=2;issue=1; spage=30; epage =37; aulast=Patil [Google Scholar].

7. Turgut $M$, Sünbül $M$, Bayirli $D$, Bilge $A$, LeblebiciogLu $\mathrm{H}$, HaznedarogLu I. Thrombocytopenia complicating the clinical course of leptospiral infection. Journal of International Medical Research 2002; 30: 535-540. Available from: https://journals.sagepub.com/doi/ pdf/10.1177/ 147323000203000511 [Google Scholar].

8. Sharma J, Suryavanshi M. Thrombocytopenia in leptospirosis and role of platelet transfusion. Asian J Transfus Sci 2007; 1(2): 52-55. [PubMed/ Google Scholar].

9. Vijayachari P, Sugunan AP, Shriram AN. Leptospirosis: An emerging global public health problem. Journal of Biosciences 2008; 33(4): 557-569. Available from: https://www.ias.ac.in/article/fulltext/ jbsc/033/04/0557-0569 [PubMed/ Google Scholar].

10. Andrade L, de Francesco Daher E, Seguro AC. Leptospiral Nephropathy. Semin Nephrol 2008; 28(4): 383-394. Available from: https://www.seminarsinnephrology. org/article/S0270-9295(08)00086-7/fulltext [PubMed/ Google Scholar].

11. Dupont H, Dupont-Perdrizet D, Perie JL, Zehner-Hansen S, Jarrige B, Daijardin JB. Leptospirosis: Prognostic Factors Associated with Mortality. Clin Infect Dis 1997; 25(3): 720-724. Available from: https://academic.oup. com/cid/article/25/3/720/291399 [PubMed/ Google Scholar].

12. Paganin F, Bourdin A, Borgherini G, Dalban C, Poubeau P, Tixier F et al. Pulmonary manifestations of leptospirosis. Rev Mal Respir 2011; 28(9): e131-e139. Available from: https://www.em-consulte.com/rmr/article/675199 [Google Scholar].

13. Panicker JN, Mammachan R, Jayakumar RV. Primary neuroleptospirosis. Postgrad Med J 2001; 77(911): 589-590. [PubMed/ Google Scholar]. 